A C T A U N IVERS I T A T S N I C O L A I C OPER N I I

EKONOMIA XLIII nr 2 (2012) 183-198

Pierwsza wersja złożona 15 października 2011

ISSN

Końcowa wersja zaakceptowana 20 listopada 2012

2080-0339

\title{
Dominik Śliwicki*
}

\section{JĄDROWY TEST LINIOWOŚCI}

\begin{abstract}
Z a r y s t r e ś c i. Celem referatu jest zaprezentowanie wyników symulacyjnego badania rozmiaru i mocy jądrowego testu liniowości, który należy do grupy testów nieparametrycznych. Badanie symulacyjne przeprowadzono dla modeli liniowych i nieliniowych, szacowanych metodą najmniejszych kwadratów oraz metodą największej wiarygodności. Uzyskane efekty porównano $\mathrm{z}$ rezultatami analogicznych symulacji dla: testu RESET, elastycznego testu Hamiltona oraz BDS.

$\mathrm{S} \nmid$ o w a k l u c z o w e: estymator jądrowy, testowanie liniowości, symulacja.

K 1 a s y f i k a c j J E L: C12, C14, C15.
\end{abstract}

\section{WSTĘP}

W ostatnich ponad dwudziestu kilku latach analiza zależności o charakterze nieliniowym cieszy się dużym zainteresowaniem. U podstaw tego zjawiska, obok rozwoju teorii ekonomii i narzędzi wnioskowania statystycznego, leży przede wszystkim rozwój technologii informatycznych, dostępność szybkich komputerów i systemów rejestrowania informacji statystycznych. Dzięki rozwojowi komputerów nastapiła popularyzacja metod wnioskowania opartych na analizach symulacyjnych czy technikach bootstrapowych, a dostępność danych o wysokiej częstotliwości obserwacji jest pomocna w wykrywaniu nieliniowości przejawiających się często jedynie w krótkich przedziałach czasu (Bruzda, 2007, s. 31).

Proces $y_{t}$ nazywany jest nieliniowym, jeżeli jego warunkowa wartość średnia lub warunkowa wariancja są dane za pomocą funkcji nieliniowych, co prowadzi do podziału procesów ekonomicznych na procesy nieliniowe w warunkowej wartości średniej oraz procesy nieliniowe w wariancji warunkowej (Osińska, 2008, s. 220). Przykładami procesów nieliniowych w warunkowej średniej są: procesy dwuliniowe, nieliniowe procesy autoregresji i średniej ru-

* Adres do korespondencji: Dominik Śliwicki, Wyższa Szkoła Gospodarki, ul. Garbary 2, 85-229 Bydgoszcz, e-mail: dominik_sliwicki@o2.pl.

(C) 2012 Wydawnictwo Uniwersytetu Mikołaja Kopernika. All rights reserved. http://www.aunc.ekonomia.umk.pl 
chomej, autoregresyjne modele progowe, przełącznikowe i wygładzonego przejścia, procesy autoregresyjne o losowych współczynnikach. Procesami o zmiennej wariancji warunkowej są procesy z rodziny GARCH oraz procesy zmienności stochastycznej (stochastic volatility) SV (Bruzda, 2007, s. 35).

Identyfikacji nieliniowości dokonuje się na podstawie testów diagnostycznych. W literaturze ekonometrycznej można spotkać szereg różnych testów liniowości, dzielących się ogólnie na dwie kategorie: testy względem określonej hipotezy alternatywnej oraz testy, które w swoim teoretycznym uzasadnieniu nie zawierają określonego modelu alternatywnego (Bruzda, 2007, s. 86). Do najczęściej stosowanych testów identyfikujących nieliniowość w warunkowej średniej, zaliczyć można m. in. test RESET, BDS, ostatnio test Hamiltona a w warunkowej wariancji test Engle'a oraz McLeoda i Li (Osińska, 2008, s. 220). Obok tych testów na znaczeniu zyskują również nieparametryczne testy oparte na estymatorach jądrowych, szczególnie test LWZ oraz testy bootstrapowe.

W referacie zaprezentowano wyniki symulacyjnego badania rozmiaru i mocy jądrowego testu liniowości LWZ w porównaniu z testami: RESET, Hamiltona i BDS.

\section{NIEPARAMETRYCZNY TEST JĄDROWY}

Nieparametryczny test jądrowy nazywany jest również testem LWZ - nazwa pochodzi od pierwszych liter nazwisk jego twórców (Li, Wang, Zheng).

Niech dana będzie zmienna losowa $Z_{t}(t=1,2, \ldots, n)$, postaci: $Z_{t}=\left(y_{t}, x_{t}\right)$, gdzie: $y_{t}$ jest skalarem, a $x_{t}$ wektorem postaci $x_{t}=\left(x_{t 1}, x_{t 2}, \ldots, x_{t d}\right)$. Wektor $x_{t}$ może zawierać opóźnione wartości $y_{t}$ oraz wartości stałe. Zależność $y_{t}$ od $x_{t}$ można zapisać w postaci:

$$
y_{t}=m\left(x_{t}\right)+\varepsilon_{t},
$$

gdzie:

$m\left(x_{t}\right) \equiv E\left(y_{t} \mid x_{t}\right)$ jest rzeczywistą ale nieznaną funkcją regresji opisującą warunkową wartość oczekiwaną zmiennej losowej $Y$,

$\varepsilon_{t}$ jest zakłóceniem losowym takim, że: $E\left(\varepsilon_{t} \mid x_{t}\right)=0$.

W teście liniowości hipoteza zerowa zakłada liniową postać zależności $m\left(x_{t}\right)$ wobec hipotezy alternatywnej głoszącej nieznaną postać nieliniową. Układ hipotez można zapisać jako (Fan, Li, 1996):

$$
\begin{aligned}
& H_{0}: m\left(x_{t}\right)=x_{t} \beta, \\
& H_{1}: m\left(x_{t}\right) \neq x_{t} \beta .
\end{aligned}
$$

Statystyka testowa ma postać (Zheng, 1996):

$$
L^{\prime}=\frac{1}{n} \sum_{t=1}^{n} \hat{\varepsilon}_{t} E\left(\hat{\varepsilon}_{t} \mid x_{t}\right) \hat{f}\left(x_{t}\right)=\frac{1}{n(n-1) h^{d}} \sum_{t=1}^{n} \sum_{t^{\prime}=1, t^{\prime} \neq t}^{n} \hat{\varepsilon}_{t} \hat{\varepsilon}_{t^{\prime}} K_{t^{\prime} t},
$$


gdzie:

$\hat{\varepsilon}_{t}=y_{t}-x_{t} \hat{\beta}-$ reszta $\mathrm{z}$ modelu liniowego,

$E\left(\hat{\varepsilon}_{t} \mid x_{t}\right)=\frac{\sum_{t^{\prime}=1, t^{\prime} \neq t}^{n} \hat{\varepsilon}_{t} K_{t^{\prime} t}}{\sum_{t^{\prime}=1, t^{\prime} \neq t}^{n} K_{t^{\prime} t}}-$ jądrowy lokalnie stały leave one out estimator proce-

su $\hat{\varepsilon}_{t}$ warunkowo względem ciągu wartości $x_{t}$,

$\hat{f}\left(x_{t}\right)=\frac{1}{(n-1) h^{d}} \sum_{t^{\prime}=1, t^{\prime} \neq t}^{n} K_{t^{\prime} t}-$ jądrowy leave one out estimator gęstości prawdopodobieństwa $x_{t}$,

$h$ - parametr wygładzania,

$K_{t^{\prime} t}=K\left(\frac{x_{t^{\prime}}-x_{t}}{h}\right)$-jądro $d$-wymiarowe.

Rozkład statystyki $L^{\prime}$ pomnożonej przez $n h^{d / 2}$ jest zbieżny do rozkładu normalnego o średniej zero oraz wariancji $\sigma^{2}$, tzn.:

$$
n h^{d / 2} L^{\prime} \rightarrow N\left(0 ; \sigma^{2}\right) \text {. }
$$

Zgodnym estymatorem asymptotycznej wariancji wyrażenia $n h^{d / 2} L^{\prime}$ jest (Li, Wang, 1998):

$$
\hat{\sigma}^{2}=\frac{2}{n(n-1) h^{d}} \sum_{t=1}^{n} \sum_{t^{\prime}=1, t^{\prime} \neq t}^{n} \hat{\varepsilon}_{t}^{2} \hat{\varepsilon}_{t^{\prime}}^{2} K_{t^{\prime} t}^{2} .
$$

Zakładając, że $\left\{Y_{t}, X_{t}^{\prime}\right\}_{t=1}^{n}$ jest procesem ściśle stacjonarnym, można dokonać standaryzacji statystyki $L^{\prime}(\mathrm{Li}, 1999)$ :

$$
L=n h^{d / 2} \frac{L^{\prime}}{\hat{\sigma}} .
$$

Asymptotyczny rozkład statystyki $L$ jest zbieżny do standardowego rozkładu normalnego $N(0 ; 1)$.

Test LWZ może być wykorzystywany jako test poprawności specyfikacji modelu. Wówczas testowaniu podlega określona postać funkcyjna modelu opisującego proces. 


\section{WYBRANE TESTY LINIOWOŚCI W WARUNKOWEJ ŚREDNIEJ}

\subsection{TEST RESET}

Test RESET (Regression Specification Error Test) został zaproponowany w 1969 roku przez Ramseya i jest on stosowany jako test diagnostyczny. Układ hipotez w tym teście jest następujący:

$\mathrm{H}_{0}$ : zależność liniowa,

$\mathrm{H}_{1}$ : zależność wielomianowa stopnia $k$.

Procedura testowania liniowości przebiega w kilku etapach. W etapie pierwszym szacuje się regresję postaci:

$$
y=\mathrm{X} \beta+\varepsilon,
$$

gdzie: $\mathrm{X}$ jest macierzą o wymiarach $n \times d$ obserwacji na zmiennych objaśniających modelu. $\mathrm{Z}$ tego modelu zapisuje się reszty $e$ oraz wartości teoretyczne $\hat{y}$. Jeżeli $\mathrm{H}_{0}$ jest prawdziwa, wówczas $\varepsilon$ jest procesem o średniej równej 0 , w sytuacji gdy nie jest prawdziwa, średnia ta jest niezerowa. Układ hipotez można zatem zapisać w postaci (Ramsey, 1969):

$$
\begin{aligned}
& \mathrm{H}_{0}: \varepsilon \sim N\left(0, \sigma^{2} \mathrm{I}\right), \\
& \mathrm{H}_{1}: \varepsilon \sim N\left(\mu, \sigma^{2} \mathrm{I}\right), \quad \mu \neq 0 .
\end{aligned}
$$

W etapie drugim szacuje się parametry modelu rozszerzonego postaci:

$$
y=X \beta+c_{2} \hat{y}^{2}+c_{3} \hat{y}^{3}+\ldots+c_{k} \hat{y}^{k}+\eta,
$$

$\mathrm{z}$ którego zapisuje się reszty $u$.

W kroku ostatnim testuje się hipotezę o liniowości postaci:

$$
\mathrm{H}_{0}: c_{2}=c_{3}=\ldots=c_{k}=0 .
$$

Statystyka sprawdzająca testu RESET przyjmuje postać:

$$
F=\frac{\left(\sum e_{t}^{2}-\sum u_{t}^{2}\right) /(k-1)}{\sum u_{t}^{2} /(n-(d+k-1))},
$$

która przy założeniu prawdziwości $\mathrm{H}_{0}$ ma asymptotyczny rozkład $F_{k-1, n-(d+k-1)}$.

\subsection{TEST HAMILTONA}

W elastycznym teście Hamiltona (flexible Hamilton test) układ hipotez można zapisać w postaci (Hamilton, 2001):

$$
\begin{aligned}
& \mathrm{H}_{0}: y_{t}=\alpha_{0}+\alpha^{\prime} \mathrm{x}_{\mathrm{t}}+\varepsilon_{t}, \\
& \mathrm{H}_{1}: y_{t}=m\left(\mathrm{x}_{\mathrm{t}}\right)+\varepsilon_{t},
\end{aligned}
$$


co oznacza, że według hipotezy zerowej proces opisywany jest modelem liniowym wobec alternatywy, że jest on opisywany niesprecyzowanym modelem nieliniowym.

Statystyka testowa ma postać:

$$
v^{2}=\frac{\left[\hat{\mathbf{\varepsilon}}^{\prime} \mathbf{H} \hat{\boldsymbol{\varepsilon}}-\sigma^{2} \operatorname{tr}(\mathbf{M H M})\right]^{2}}{\sigma^{4}\left(2 \operatorname{tr}\left\{\left[\mathbf{M H M}-(n-d-1)^{-1} \mathbf{M} \operatorname{tr}(\mathbf{M H M})\right]^{2}\right\}\right)},
$$

gdzie:

$\mathbf{H}$ - macierz $(n \times n)$ kowariancji o elementach $(t, s)$ określonych wzorem:

$\mathrm{H}_{d}\left(\frac{1}{2}\left[g_{1}^{2}\left(x_{1 t}-x_{1 s}\right)^{2}+g_{2}^{2}\left(x_{2 t}-x_{2 s}\right)^{2}+\ldots+g_{d}^{2}\left(x_{d t}-x_{d s}\right)^{2}\right]^{1 / 2}\right)$,

$g_{i}=2 / \sqrt{d s_{i}^{2}}$,

$d$ - liczba zmiennych bez stałej występujących w modelu,

$s_{i}$ - odchylenie standardowe $i$ - tej zmiennej objaśniającej,

$\mathbf{M}=\mathbf{I}_{\mathrm{n}}-\mathbf{X}\left(\mathbf{X}^{\prime} \mathbf{X}\right)^{-1} \mathbf{X}^{\prime}-$ macierz rzutowania o wymiarach $(n \times n)$,

$\mathbf{I}_{\mathbf{n}}-$ macierz jednostkowa stopnia $n$,

$\mathbf{X}$ - macierz obserwacji na zmiennych objaśniających modelu,

$\hat{\boldsymbol{\varepsilon}}$ - wektor reszt z modelu liniowego,

$\sigma^{2}$ - wariancja resztowa $\mathrm{z}$ modelu liniowego,

$H_{d}(c)$ - funkcja zależna od $d$ postaci:

$$
\begin{array}{ll}
H_{d}(c)=\left\{\begin{array}{cl}
1-c & d=1 \\
1-(2 / \pi)\left[c\left(1-c^{2}\right)^{1 / 2}+\arcsin (c)\right] & d=2 \\
1-3 c / 2+c^{3} / 2 & d=3 \\
1-(2 / \pi)\left[(2 / 3) c\left(1-c^{2}\right)^{3 / 2}+c\left(1-c^{2}\right)^{1 / 2}+\arcsin (c)\right] & d=4 \\
1-3 c / 2+c^{3} / 2-(3 c / 8)\left(1-c^{2}\right)^{2} & d=5
\end{array}\right. \\
H_{d}(c)=\operatorname{cov}\left(m(\mathrm{x}), m(\mathrm{z})\left[(\mathrm{x}-\mathrm{z})^{\prime}(\mathrm{x}-\mathrm{z})\right]^{1 / 2}\right), & \\
{\left[(\mathrm{x}-\mathrm{z})^{\prime}(\mathrm{x}-\mathrm{z})\right]^{1 / 2}=2 c,} & \\
c-\text { połowa odległości między wektorami x i z. }
\end{array}
$$

Dla każdej wartości $d$, funkcja $H_{d}(c)$ przyjmuje wartość 1 gdy $c=0$ oraz 0 gdy $c \geq 1$.

Asymptotyczny rozkład statystyki $v^{2}$ jest zbieżny do rozkładu $\chi^{2}(1)$.

\subsection{TEST BDS}

Test BDS jest testem służącym do badania występowania zależności w szeregach czasowych. Może być stosowany do testowania możliwych odstępstw 
od niezależności badanego szeregu w tym zależności liniowych, zależności nieliniowych oraz chaosu. Idea testu jest stosunkowo prosta. Hipoteza zerowa głosi, że analizowany szereg jest ciaggiem niezależnych zmiennych losowych o jednakowych rozkładach (independently iidentically distributed). W przypadku testowania liniowości, badaniu poddaje się reszty z modelu liniowego i jeżeli model ten dobrze dopasowuje się do szeregu czasowego, to mają one niezależne i jednakowe rozkłady. Niespełnienie tego warunku oznacza, że w analizowanym szeregu występuje bliżej niesprecyzowana nieliniowość (Osińska, 2008, s. 233-234).

Jeżeli przez $Y_{t, m}$ oznaczy się ciąg kolejnych wektorów pochodzących z szeregu $y_{t}$, takich że $Y_{t, m}=\left[y_{t}, y_{t+1}, \ldots, y_{t+m-1}\right]$, to para wektorów $Y_{s, m}, Y_{t, m}$ znajduje się w odległości nie większej niż $\varepsilon$, gdy (Brock, Deckert, Scheinkman, 1986):

$$
\left|y_{s+j}-y_{t+j}\right| \leq \varepsilon \text { dla } j=0,1, \ldots, m-1,
$$

gdzie:

$m$ - jest parametrem zanurzenia.

Statystyka testowa przyjmuje postać:

$$
B D S=\sqrt{n-m+1}\left(C_{m}(\varepsilon)-C_{1}(\varepsilon)^{m}\right),
$$

gdzie:

$C_{m}(\varepsilon)$ - oznacza całkę korelacyjną postaci:

$$
\begin{aligned}
& C_{m}(\varepsilon)=\frac{2}{(n-m+1)(n-m)} \sum_{s=1}^{n-m+1} \sum_{t=s+1}^{n-m+1} \prod_{j=0}^{m-1} I\left(y_{s+j}, y_{t+j}\right), \\
& I\left(y_{s+j}, y_{t+j}\right)=\left\{\begin{array}{l}
1 ;\left|y_{s+j}-y_{t+j}\right| \leq \varepsilon \\
0 ;\left|y_{s+j}-y_{t+j}\right|>\varepsilon
\end{array} .\right.
\end{aligned}
$$

Statystyka BDS posiada rozkład normalny o średniej 0 oraz wariancji $\sigma^{2}(\varepsilon)$ wyrażającej się wzorem (Brock, Hsieh, LeBaron, 1991):

$$
\sigma^{2}(\varepsilon)=4\left(k^{m}+2 \sum_{j=1}^{m-1} k^{m-j} c_{1}^{2 j}+(m-1)^{2} c_{1}^{2 m}-m^{2} k c_{1}^{2 m-2}\right),
$$

gdzie:

$k$ - jest prawdopodobieństwem, że dowolna trójka punktów znajduje się względem siebie w odległości mniejszej niż $\varepsilon$,

$$
k_{n}(\varepsilon)=\frac{2}{n(n-1)(n-2)} \sum_{t=1}^{n} \sum_{s=t+1}^{n} \sum_{r=s+1}^{n}\left(\begin{array}{r}
I\left(y_{t}, y_{s}\right) I\left(y_{s}, y_{r}\right)+I\left(y_{t}, y_{r}\right) I\left(y_{r}, y_{s}\right)+ \\
+I\left(y_{s}, y_{t}\right) I\left(y_{t}, y_{r}\right)
\end{array}\right) .
$$

Dysponując wariancją, można dokonać standaryzacji statystyki BDS do postaci: 


$$
\sqrt{n-m+1} \frac{\left(C_{m}(\varepsilon)-C_{1}(\varepsilon)^{m}\right)}{\sigma(\varepsilon)} \rightarrow N(0,1) .
$$

Podkreślić należy, że test ten jest wrażliwy na wybór $m$ oraz $\varepsilon$ i nie powinien być stosowany do szeregów, w których liczba obserwacji jest mniejsza od 200 (Osińska, 2008, s. 234).

\section{ZAŁOŻENIA EKSPERYMENTU SYMULACYJNEGO}

Do badania zostały wybrane często stosowane postacie modeli ekonometrycznych, które reprezentują możliwe relacje pomiędzy zjawiskami ekono-

micznymi. Szeregi generowano dla trzech liczebności prób: 250, 500 i 1000 obserwacji. Obliczenia zostały wykonane w programie EViews.

1. Modele liniowe:

a) szacowane metodą najmniejszych kwadratów:

- $y_{t}=0,8 y_{t-2}+\varepsilon_{t}$,

- $y_{t}=0,8 x_{t}+0,5 y_{t-1}+\varepsilon_{t}$,

- $y_{t}=0,6 x_{t}-0,3 x_{t-1}+\varepsilon_{t}$,

b) szacowane metodą największej wiarygodności:

- $y_{t}=-0,5 \varepsilon_{t-1}+0,4 \varepsilon_{t-2}+\varepsilon_{t}$,

- $y_{t}=0,7 y_{t-1}+0,2 \varepsilon_{t-1}+\varepsilon_{t}$,

- $y_{t}=0,8 x_{t}+0,6 y_{t-1}-0,3 \varepsilon_{t-1}+\varepsilon_{t}$,

gdzie: $x_{t}, \varepsilon_{t} \sim N(0 ; 1)$.

2. Modele nieliniowe:

a) szacowane metodą najmniejszych kwadratów:

- $y_{t}=0,5 x_{t} y_{t-1}+\varepsilon_{t}$,

- $y_{t}=0,2 y_{t-1} y_{t-2}+\varepsilon_{t}$,

- $y_{t}=\left\{\begin{array}{l}-0,1+0,2 y_{t-1}-0,7 y_{t-2}+\varepsilon_{t} ; y_{t-2} \geq 0 \\ 0,2-0,5 y_{t-1}+0,4 y_{t-2}+\varepsilon_{t} ; y_{t-2}<0\end{array}\right.$,

b) szacowane metodą największej wiarygodności:

- $y_{t}=0,6 y_{t-1} \varepsilon_{t-2}+\varepsilon_{t}$,

- $y_{t}=0,5 \varepsilon_{t-1}-0,3 \varepsilon_{t-2}+0,5 \varepsilon_{t-1} \varepsilon_{t-2}+\varepsilon_{t}$,

- $y_{t}=0,5 y_{t-1}-0,4 y_{t-1} \varepsilon_{t-1}+0,3 \varepsilon_{t-1}+\varepsilon_{t}$,

gdzie: $x_{t}, \varepsilon_{t} \sim N(0 ; 1)$.

Parametry wygładzające jądrowych estymatorów warunkowej średniej zostały wyznaczone za pomocą wzoru (Silverman, 1986):

$$
h_{i}=0,9 \min \left(s_{i}, \frac{q_{3 i}-q_{1 i}}{1,349}\right) n^{-1 / d+4},
$$


gdzie:

$s_{i}$ - odchylenie standardowe $i$ - tej zmiennej objaśniającej modelu, $i=1, \ldots, d$,

$d$ - liczba zmiennych objaśniających modelu,

$q_{j i}-j$ - ty kwartyl rozkładu $i$ - tej zmiennej objaśniającej.

Badanie przeprowadzono przy założeniu, że znana jest struktura szeregów zaś nieznana postać funkcyjna zależności między ich poszczególnymi składowymi. Na podstawie generowanych szeregów wyznaczano statystyki testu LWZ, testu RESET dla zależności kwadratowej i wielomianowej stopnia trzeciego, testu Hamiltona i testu BDS dla parametru zanurzenia równego 2, 3 i 4 oraz wartości parametru $\varepsilon$ równemu odchyleniu standardowemu $\mathrm{z}$ reszt modelu liniowego. Dla każdego z tych testów i każdej długości szeregu wyznaczono procent odrzuceń hipotezy o liniowości, przyjmując poziomy istotności równe $1 \%, 2 \%$, $5 \%$ i $10 \%$. W przypadku liniowych modeli generujących liczba odrzuceń hipotezy o liniowości powinna być jak najmniejsza, a w przypadku nieliniowych jak największa.

\section{WYNIKI BADAŃ SYMULACYJNYCH}

Tabele 1-4. zawierają procentowe wartości odrzuceń hipotezy o liniowości dla liniowych i nieliniowych modeli generujących. W tabelach wyróżniono wartości mniejsze bądź równe zakładanemu poziomowi istotności $\alpha$ (rozmiar testu) w przypadkach, gdy model procesu generującego był liniowy oraz wartości większe od $1-\alpha$ (moc testu), gdy model procesu generującego był nieliniowy.

Tabela 1. Procent odrzuceń hipotezy o liniowości, gdy procesami generującymi były modele liniowe szacowane metodą najmniejszych kwadratów

\begin{tabular}{|c|c|c|c|c|c|c|c|c|}
\hline \multirow{2}{*}{$\begin{array}{c}\text { Liczba } \\
\text { obserwacji } \\
n\end{array}$} & $\begin{array}{c}\text { Poziom } \\
\text { istotności } \alpha\end{array}$ & LWZ & RESET^2 & RESET^3 & HAMILTON & BDS-2 & BDS-3 & BDS-4 \\
\hline 250 & $10 \%$ & $\mathbf{4 , 3 3}$ & $\mathbf{7 , 7 7}$ & $\mathbf{6 , 8 9}$ & $\mathbf{6 , 6 7}$ & 13,66 & 13,25 & 13,03 \\
& $5 \%$ & $\mathbf{2 , 7 9}$ & $\mathbf{3 , 5 8}$ & $\mathbf{2 , 4 1}$ & $\mathbf{4 , 8 7}$ & 7,24 & 7,24 & 6,91 \\
& $2 \%$ & $\mathbf{1 , 7 4}$ & $\mathbf{1 , 2 9}$ & $\mathbf{0 , 5 3}$ & 3,22 & 3,39 & 3,14 & 3,01 \\
& $1 \%$ & 1,35 & $\mathbf{0 , 7 5}$ & $\mathbf{0 , 1 5}$ & 2,58 & 2,02 & 1,69 & 1,68 \\
& $1 \%$ & 1,35 & $\mathbf{0 , 7 5}$ & $\mathbf{0 , 1 5}$ & 2,58 & 2,02 & 1,69 & 1,68 \\
\hline \multirow{2}{5}{500} & $10 \%$ & $\mathbf{4 , 9 9}$ & $\mathbf{9 , 2 2}$ & $\mathbf{7 , 2 6}$ & $\mathbf{6 , 5 9}$ & 11,97 & 11,42 & 11,42 \\
& $5 \%$ & $\mathbf{3 , 1 5}$ & $\mathbf{4 , 3 7}$ & $\mathbf{2 , 3 0}$ & $\mathbf{4 , 5 5}$ & 6,08 & 5,94 & 5,90 \\
& $2 \%$ & $\mathbf{1 , 9 7}$ & $\mathbf{1 , 5 1}$ & $\mathbf{0 , 4 5}$ & 3,11 & 2,48 & 2,45 & 2,68 \\
& $1 \%$ & 1,45 & $\mathbf{0 , 6 7}$ & $\mathbf{0 , 1 4}$ & 2,48 & 1,28 & 1,37 & 1,46 \\
\hline 1000 & $10 \%$ & $\mathbf{5 , 8 5}$ & $\mathbf{9 , 2 1}$ & $\mathbf{6 , 7 6}$ & $\mathbf{6 , 6 8}$ & 10,51 & 10,69 & 10,97 \\
& $5 \%$ & $\mathbf{3 , 6 0}$ & $\mathbf{4 , 4 1}$ & $\mathbf{2 , 4 9}$ & $\mathbf{4 , 6 8}$ & 5,45 & 5,75 & 5,76 \\
& $2 \%$ & 2,26 & $\mathbf{1 , 7 2}$ & $\mathbf{0 , 6 0}$ & 3,10 & 2,41 & 2,32 & 2,33 \\
& $1 \%$ & 1,69 & $\mathbf{0 , 9 7}$ & $\mathbf{0 , 2 0}$ & 2,49 & 1,30 & 1,24 & 1,12 \\
\hline
\end{tabular}


Ciąg dalszy tabeli 1

\begin{tabular}{|c|c|c|c|c|c|c|c|c|}
\hline \multirow[b]{2}{*}{$n$} & \multicolumn{8}{|c|}{$y_{t}=0,8 x_{t}+0,5 y_{t-1}+\varepsilon_{t}$} \\
\hline & $\begin{array}{c}\text { Poziom } \\
\text { istotności } \alpha\end{array}$ & LWZ & RESET $^{\wedge} 2$ & RESET^3 & HAMILTON & BDS-2 & BDS-3 & BDS-4 \\
\hline \multirow[t]{4}{*}{250} & $10 \%$ & 7,90 & 9,67 & 6,48 & 6,43 & 12,76 & 12,99 & 12,98 \\
\hline & $5 \%$ & 3,49 & 4,50 & 1,99 & 4,75 & 6,73 & 6,84 & 6,87 \\
\hline & $2 \%$ & 1,43 & 1,83 & 0,41 & 3,39 & 3,11 & 2,97 & 3,04 \\
\hline & $1 \%$ & 0,92 & 0,85 & 0,15 & 2,67 & 1,50 & 1,73 & 1,58 \\
\hline \multirow[t]{4}{*}{500} & $10 \%$ & 7,91 & 9,74 & 6,74 & 6,39 & 12,14 & 11,90 & 11,74 \\
\hline & $5 \%$ & 3,78 & 4,69 & 1,91 & 4,32 & 6,44 & 6,40 & 6,46 \\
\hline & $2 \%$ & 1,49 & 1,99 & 0,46 & 3,04 & 2,81 & 3,09 & 2,90 \\
\hline & $1 \%$ & 1,02 & 0,99 & 0,15 & 2,31 & 1,62 & 1,71 & 1,70 \\
\hline \multirow[t]{4}{*}{1000} & $10 \%$ & 8,53 & 9,89 & 6,46 & 6,62 & 10,92 & 11,62 & 12,14 \\
\hline & $5 \%$ & 3,73 & 4,93 & 2,10 & 4,42 & 5,46 & 5,91 & 6,42 \\
\hline & $2 \%$ & 1,55 & 1,87 & 0,40 & 3,13 & 2,20 & 2,57 & 2,93 \\
\hline & $1 \%$ & 1,08 & 0,88 & 0,14 & 2,34 & 1,19 & 1,38 & 1,58 \\
\hline & \multicolumn{8}{|c|}{$y_{t}=0,6 x_{t}-0,3 x_{t-1}+\varepsilon_{t}$} \\
\hline$n$ & $\begin{array}{c}\text { Poziom } \\
\text { istotności } \alpha\end{array}$ & LWZ & RESET^2 & 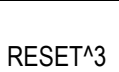 & HAMILTON & BDS-2 & BDS-3 & BDS-4 \\
\hline \multirow[t]{4}{*}{250} & $10 \%$ & 6,97 & 10,43 & 6,53 & 6,72 & 12,93 & 12,80 & 12,73 \\
\hline & $5 \%$ & 2,88 & 4,87 & 2,23 & 4,64 & 7,04 & 7,09 & 7,05 \\
\hline & $2 \%$ & 1,27 & 1,99 & 0,49 & 3,20 & 3,23 & 3,27 & 3,20 \\
\hline & $1 \%$ & 0,76 & 1,06 & 0,16 & 2,45 & 1,62 & 1,86 & 1,78 \\
\hline \multirow[t]{4}{*}{500} & $10 \%$ & 7,89 & 9,68 & 6,93 & 6,35 & 10,91 & 11,12 & 11,77 \\
\hline & $5 \%$ & 3,55 & 4,67 & 2,21 & 4,53 & 5,77 & 5,52 & 5,85 \\
\hline & $2 \%$ & 1,61 & 2,03 & 0,56 & 3,10 & 2,37 & 2,26 & 2,23 \\
\hline & $1 \%$ & 1,06 & 1,00 & 0,13 & 2,50 & 1,16 & 1,18 & 1,06 \\
\hline \multirow[t]{4}{*}{1000} & $10 \%$ & 8,54 & 9,55 & 6,29 & 6,67 & 10,75 & 10,95 & 11,12 \\
\hline & $5 \%$ & 3,77 & 4,71 & 1,96 & 4,66 & 5,49 & 5,55 & 5,52 \\
\hline & $2 \%$ & 1,69 & 1,85 & 0,39 & 3,13 & 2,26 & 2,20 & 2,27 \\
\hline & $1 \%$ & 0,99 & 0,91 & 0,08 & 2,30 & 1,15 & 1,08 & 1,22 \\
\hline
\end{tabular}

Źródło: Śliwicki D. (2010), Estymacja jądrowa w analizie ekonometrycznej, Torun, niepublikowana praca doktorska.

W grupie modeli liniowych szacowanych metodą najmniejszych kwadratów, test LWZ dał wyniki lepsze w porównaniu z testem RESET dla zależności wielomianowej stopnia drugiego i nieco gorsze dla zależności wielomianowej stopnia trzeciego. W porównaniu z testem Hamiltona, test LWZ na ogół częściej odrzucał hipotezę o liniowości dla $10 \%$ poziomu istotności oraz rzadziej dla $5 \%$. Test BDS w każdym przypadku przekroczył zakładane nominalne poziomy istotności i w związku z tym daje on wyniki gorsze aniżeli test LWZ. Dla każdego modelu rozmiar testu rośnie wraz ze wzrostem liczebności próby. Test LWZ przekraczał najczęściej 1\% poziom istotności. 
Tabela 2. Procent odrzuceń hipotezy o liniowości, gdy procesami generującymi były modele liniowe szacowane metodą największej wiarygodności

\begin{tabular}{|c|c|c|c|c|c|c|c|c|}
\hline \multirow{2}{*}{$\begin{array}{c}\text { Liczba } \\
\text { obserwacji } \\
n \\
\end{array}$} & \multicolumn{8}{|c|}{$y_{t}=-0,5 \varepsilon_{t-1}+0,4 \varepsilon_{t-2}+\varepsilon_{t}$} \\
\hline & $\begin{array}{c}\text { Poziom } \\
\text { istotności } \alpha\end{array}$ & LWZ & RESET^2 & RESET^3 & HAMILTON & BDS-2 & BDS-3 & BDS-4 \\
\hline \multirow[t]{4}{*}{250} & $10 \%$ & 7,01 & 10,05 & 7,60 & 7,42 & 13,34 & 14,01 & 14,06 \\
\hline & $5 \%$ & 2,91 & 5,04 & 2,56 & 5,24 & 7,24 & 7,52 & 7,80 \\
\hline & $2 \%$ & 1,50 & 2,10 & 0,53 & 3,50 & 2,98 & 3,36 & 3,32 \\
\hline & $1 \%$ & 0,98 & 0,95 & 0,17 & 2,68 & 1,60 & 1,80 & 1,63 \\
\hline \multirow[t]{4}{*}{500} & $10 \%$ & 8,01 & 10,28 & 6,66 & 7,42 & 10,89 & 11,20 & 11,36 \\
\hline & $5 \%$ & 3,72 & 4,83 & 2,21 & 5,21 & 5,56 & 5,57 & 5,50 \\
\hline & $2 \%$ & 1,73 & 2,07 & 0,42 & 3,57 & 2,41 & 2,18 & 2,17 \\
\hline & $1 \%$ & 1,15 & 1,19 & 0,11 & 2,83 & 1,14 & 1,10 & 1,20 \\
\hline \multirow[t]{4}{*}{1000} & $10 \%$ & 8,14 & 9,83 & 6,69 & 7,58 & 11,21 & 11,43 & 11,10 \\
\hline & $5 \%$ & 3,92 & 5,22 & 2,04 & 5,39 & 5,93 & 6,16 & 6,01 \\
\hline & $2 \%$ & 1,77 & 2,10 & 0,51 & 3,80 & 2,51 & 2,65 & 2,51 \\
\hline & $1 \%$ & 1,04 & 0,97 & 0,14 & 2,95 & 1,24 & 1,31 & 1,36 \\
\hline \multirow[b]{2}{*}{$n$} & \multicolumn{8}{|c|}{$y_{t}=0,7 y_{t-1}+0,2 \varepsilon_{t-1}+\varepsilon_{t}$} \\
\hline & $\begin{array}{c}\text { Poziom } \\
\text { istotności } \alpha\end{array}$ & LWZ & RESET^2 & RESET^3 & HAMILTON & BDS-2 & BDS-3 & BDS-4 \\
\hline \multirow[t]{4}{*}{250} & $10 \%$ & 7,28 & 9,51 & 6,08 & 6,74 & 13,35 & 13,79 & 13,40 \\
\hline & $5 \%$ & 3,10 & 4,50 & 2,11 & 4,99 & 7,25 & 7,77 & 7,47 \\
\hline & $2 \%$ & 1,40 & 1,88 & 0,40 & 3,49 & 3,29 & 3,28 & 3,52 \\
\hline & $1 \%$ & 0,98 & 0,86 & 0,16 & 2,76 & 1,82 & 1,89 & 1,75 \\
\hline \multirow[t]{4}{*}{500} & $10 \%$ & 7,19 & 9,77 & 6,86 & 6,53 & 11,35 & 11,50 & 11,20 \\
\hline & $5 \%$ & 3,19 & 4,91 & 2,13 & 4,78 & 6,15 & 5,69 & 5,93 \\
\hline & $2 \%$ & 1,40 & 1,99 & 0,39 & 3,24 & 2,81 & 2,66 & 2,55 \\
\hline & $1 \%$ & 0,90 & 1,00 & 0,06 & 2,54 & 1,53 & 1,39 & 1,32 \\
\hline \multirow[t]{4}{*}{1000} & $10 \%$ & 8,11 & 9,95 & 6,03 & 6,20 & 11,26 & 11,02 & 11,14 \\
\hline & $5 \%$ & 3,68 & 4,83 & 1,94 & 4,30 & 5,94 & 5,64 & 5,49 \\
\hline & $2 \%$ & 1,58 & 1,82 & 0,47 & 3,04 & 2,61 & 2,34 & 2,48 \\
\hline & $1 \%$ & 1,09 & 0,98 & 0,13 & 2,47 & 1,17 & 1,18 & 1,42 \\
\hline & \multicolumn{8}{|c|}{$y_{t}=0,8 x_{t}+0,6 y_{t-1}-0,3 \varepsilon_{t-1}+\varepsilon_{t}$} \\
\hline$n$ & $\begin{array}{c}\text { Poziom } \\
\text { istotności } \alpha\end{array}$ & LWZ & RESET^2 & RESET^3 & HAMILTON & BDS-2 & BDS-3 & BDS-4 \\
\hline \multirow[t]{4}{*}{250} & $10 \%$ & 8,47 & 10,02 & 7,06 & 7,45 & 13,01 & 13,54 & 12,72 \\
\hline & $5 \%$ & 3,96 & 4,92 & 2,45 & 4,31 & 7,12 & 7,22 & 7,22 \\
\hline & $2 \%$ & 1,58 & 1,93 & 0,59 & 2,43 & 3,17 & 3,28 & 3,26 \\
\hline & $1 \%$ & 0,97 & 1,06 & 0,19 & 1,74 & 1,61 & 1,71 & 1,78 \\
\hline \multirow[t]{4}{*}{500} & $10 \%$ & 8,50 & 9,96 & 6,93 & 7,85 & 12,01 & 11,54 & 11,57 \\
\hline & $5 \%$ & 3,75 & 4,99 & 2,17 & 4,74 & 5,98 & 5,97 & 5,99 \\
\hline & $2 \%$ & 1,51 & 1,98 & 0,41 & 2,85 & 2,46 & 2,45 & 2,23 \\
\hline & $1 \%$ & 0,84 & 1,01 & 0,10 & 2,07 & 1,31 & 1,27 & 1,14 \\
\hline
\end{tabular}


Ciagg dalszy tabeli 2

\begin{tabular}{|c|c|c|c|c|c|c|c|c|}
\hline 1000 & $10 \%$ & $\mathbf{9 , 0 8}$ & $\mathbf{9 , 9 9}$ & $\mathbf{6 , 4 5}$ & $\mathbf{7 , 2 1}$ & 10,85 & 10,69 & 10,53 \\
& $5 \%$ & $\mathbf{4 , 3 7}$ & 5,06 & $\mathbf{1 , 9 9}$ & $\mathbf{4 , 2 1}$ & 5,59 & 5,46 & 5,35 \\
& $2 \%$ & $\mathbf{1 , 7 1}$ & $\mathbf{1 , 9 6}$ & $\mathbf{0 , 4 0}$ & 2,42 & 2,38 & 2,33 & 2,23 \\
& $1 \%$ & 1,05 & $\mathbf{0 , 8 2}$ & $\mathbf{0 , 1 1}$ & 1,73 & 1,16 & 1,09 & 1,07 \\
\hline
\end{tabular}

Źródło: Śliwicki D. (2010), Estymacja jądrowa w analizie ekonometrycznej, Toruń, niepublikowana praca doktorska.

Dla grupy modeli liniowych szacowanych metodą największej wiarygodności można wyciągnąć wnioski analogicznych do tych, sformułowanych dla modeli liniowych szacowanych metodą najmniejszych kwadratów. Test LWZ dał wyniki lepsze w porównaniu $\mathrm{z}$ testem RESET dla zależności wielomianowej stopnia drugiego i nieco gorsze dla zależności wielomianowej stopnia trzeciego. W porównaniu z testem Hamiltona, test LWZ na ogół częściej odrzucał hipotezę o liniowości dla $10 \%$ poziomu istotności oraz rzadziej dla 5\%. Test BDS w każdym przypadku przekroczył zakładane nominalne poziomy istotności i w związku z tym daje on wyniki gorsze aniżeli test LWZ. Dla każdego modelu rozmiar testu LWZ rośnie wraz ze wzrostem liczebności próby. Test LWZ przekraczał najczęściej $1 \%$ poziom istotności.

Tabela 3. Procent odrzuceń hipotezy o liniowości, gdy procesami generującymi były modele nieliniowe szacowane metodą najmniejszych kwadratów

\begin{tabular}{|c|c|c|c|c|c|c|c|c|}
\hline \multirow{2}{*}{$\begin{array}{c}\text { Liczba } \\
\text { obserwacji } \\
n\end{array}$} & \multicolumn{8}{|c|}{$y_{t}=0,5 x_{t} y_{t-1}+\varepsilon_{t}$} \\
\hline & $\begin{array}{c}\text { Poziom } \\
\text { istotności } \alpha\end{array}$ & LWZ & RESET^2 & RESET $^{\wedge} 3$ & HAMILTON & BDS-2 & BDS-3 & BDS-4 \\
\hline \multirow[t]{4}{*}{250} & $10 \%$ & 87,96 & 73,86 & 70,75 & 97,55 & 81,74 & 76,87 & 70,98 \\
\hline & $5 \%$ & 83,05 & 68,43 & 61,04 & 95,62 & 75,29 & 69,48 & 63,26 \\
\hline & $2 \%$ & 76,20 & 61,67 & 49,43 & 92,35 & 66,53 & 60,04 & 53,50 \\
\hline & $1 \%$ & 71,04 & 57,08 & 41,31 & 89,50 & 59,87 & 54,14 & 46,88 \\
\hline \multirow[t]{4}{*}{500} & $10 \%$ & 99,82 & 82,72 & 81,66 & 100,00 & 97,94 & 96,31 & 93,51 \\
\hline & $5 \%$ & 99,70 & 78,90 & 75,76 & 100,00 & 96,26 & 94,01 & 90,20 \\
\hline & $2 \%$ & 99,25 & 74,65 & 68,59 & 100,00 & 93,55 & 90,00 & 84,67 \\
\hline & $1 \%$ & 98,67 & 71,77 & 63,45 & 99,99 & 90,96 & 86,33 & 80,27 \\
\hline \multirow[t]{4}{*}{1000} & $10 \%$ & 100,00 & 87,75 & 87,61 & 100,00 & 99,99 & 99,95 & 99,72 \\
\hline & $5 \%$ & 100,00 & 85,22 & 83,88 & 100,00 & 99,98 & 99,89 & 99,57 \\
\hline & $2 \%$ & 100,00 & 82,52 & 79,38 & 100,00 & 99,89 & 99,66 & 99,17 \\
\hline & $1 \%$ & 100,00 & 80,83 & 76,17 & 100,00 & 99,83 & 99,41 & 98,38 \\
\hline & \multicolumn{8}{|c|}{$y_{t}=0,2 y_{t-1} y_{t-2}+\varepsilon_{t}$} \\
\hline$n$ & $\begin{array}{c}\text { Poziom } \\
\text { istotności } \alpha\end{array}$ & LWZ & RESET^2 & RESET^3 & HAMILTON & BDS-2 & BDS-3 & BDS-4 \\
\hline \multirow[t]{4}{*}{250} & $10 \%$ & 12,53 & 42,85 & 34,46 & 22,38 & 21,65 & 24,20 & 24,00 \\
\hline & $5 \%$ & 8,06 & 32,32 & 19,96 & 16,43 & 14,58 & 17,20 & 16,96 \\
\hline & $2 \%$ & 4,87 & 22,19 & 9,14 & 11,63 & 8,81 & 11,51 & 11,07 \\
\hline & $1 \%$ & 3,49 & 16,43 & 5,13 & 8,86 & 6,45 & 8,67 & 8,14 \\
\hline
\end{tabular}


Ciagg dalszy tabeli 3

\begin{tabular}{|c|c|c|c|c|c|c|c|c|}
\hline \multirow[t]{4}{*}{500} & $10 \%$ & 24,49 & 54,52 & 49,62 & 46,96 & 27,13 & 33,74 & 33,37 \\
\hline & $5 \%$ & 17,96 & 45,89 & 35,34 & 37,71 & 19,44 & 25,59 & 24,71 \\
\hline & $2 \%$ & 12,09 & 35,67 & 21,08 & 29,17 & 12,52 & 17,52 & 16,70 \\
\hline & $1 \%$ & 8,99 & 29,06 & 13,82 & 23,94 & 9,28 & 12,99 & 12,71 \\
\hline \multirow[t]{4}{*}{1000} & $10 \%$ & 51,07 & 71,20 & 68,04 & 86,25 & 38,57 & 50,90 & 50,21 \\
\hline & $5 \%$ & 41,72 & 64,98 & 56,82 & 80,32 & 30,13 & 41,61 & 41,03 \\
\hline & $2 \%$ & 32,08 & 57,44 & 43,41 & 72,02 & 21,44 & 31,57 & 30,78 \\
\hline & $1 \%$ & 26,24 & 51,99 & 34,84 & 66,26 & 16,35 & 25,18 & 24,67 \\
\hline \multirow[b]{2}{*}{$n$} & \multicolumn{8}{|c|}{$\begin{array}{l}-0,1+0,2 y_{t-1}-0,7 y_{t-2} ; y_{t-2} \geq 0 \\
0,2-0,5 y_{t-1}+0,4 y_{t-2} ; y_{t-2}<0\end{array}+\varepsilon_{t}$} \\
\hline & $\begin{array}{c}\text { Poziom } \\
\text { istotności } \alpha \\
\end{array}$ & LWZ & RESET^2 & RESET^3 & HAMILTON & BDS-2 & BDS-3 & BDS-4 \\
\hline \multirow[t]{4}{*}{250} & $10 \%$ & 99,94 & 16,20 & 16,08 & 99,99 & 47,90 & 80,98 & 85,97 \\
\hline & $5 \%$ & 99,89 & 9,58 & 7,13 & 99,98 & 39,09 & 74,85 & 80,74 \\
\hline & $2 \%$ & 99,83 & 4,79 & 2,07 & 99,97 & 30,06 & 66,01 & 73,35 \\
\hline & $1 \%$ & 99,76 & 2,84 & 0,82 & 99,95 & 24,36 & 59,35 & 67,80 \\
\hline \multirow[t]{4}{*}{500} & $10 \%$ & 100,00 & 20,51 & 28,94 & 100,00 & 72,05 & 97,84 & 98,92 \\
\hline & $5 \%$ & 100,00 & 12,56 & 14,70 & 100,00 & 63,90 & 96,53 & 98,10 \\
\hline & $2 \%$ & 100,00 & 6,74 & 5,60 & 100,00 & 54,05 & 93,62 & 96,50 \\
\hline & $1 \%$ & 100,00 & 4,24 & 2,44 & 100,00 & 46,92 & 90,82 & 94,93 \\
\hline \multirow[t]{4}{*}{1000} & $10 \%$ & 100,00 & 27,41 & 52,94 & 100,00 & 93,19 & 99,95 & 99,98 \\
\hline & $5 \%$ & 100,00 & 18,35 & 34,51 & 100,00 & 89,55 & 99,94 & 99,98 \\
\hline & $2 \%$ & 100,00 & 10,18 & 16,91 & 100,00 & 83,94 & 99,94 & 99,98 \\
\hline & $1 \%$ & 100,00 & 6,56 & 9,01 & 100,00 & 78,85 & 99,76 & 99,94 \\
\hline
\end{tabular}

Źródło: Śliwicki D. (2010), Estymacja jądrowa w analizie ekonometrycznej, Toruń, niepublikowana praca doktorska.

W grupie modeli nieliniowych szacowanych metodą najmniejszych kwadratów test LWZ osiagnął 100\% moc dla szeregów długości 1000 obserwacji. Wyjątek stanowi model NLAR(2), dla którego żaden z testów nie osiagnął zadowalającej mocy i trudno wskazać przewagę któregokolwiek z nich nad pozostałymi. Jedynie w przypadku modelu SETAR(2) test LWZ wykazuje wysoką moc dla każdej liczebności prób. W przypadku modelu nieliniowego postaci: $y_{t}=0,5 x_{t} y_{t-1}+\varepsilon_{t}$ test LWZ wykazuje moc dla szeregów 500 obserwacji. $\mathrm{W}$ porównaniu $\mathrm{z}$ testem Hamiltona test LWZ wykazuje nieco niższą moc. W porównaniu $\mathrm{z}$ testami RESET i BDS test LWZ zachowuje się lepiej. 
Tabela 4. Procent odrzuceń hipotezy o liniowości, gdy procesami generującymi były modele nieliniowe szacowane metodą największej wiarygodności

\begin{tabular}{|c|c|c|c|c|c|c|c|c|}
\hline \multirow{2}{*}{\begin{tabular}{|c} 
Liczba \\
obserwacji \\
$n$
\end{tabular}} & \multicolumn{8}{|c|}{$y_{t}=0,6 y_{t-1} \varepsilon_{t-2}+\varepsilon_{t}$} \\
\hline & $\begin{array}{c}\text { Poziom } \\
\text { istotności } \alpha\end{array}$ & LWZ & RESET^2 & RESET^3 $^{\wedge}$ & HAMILTON & BDS-2 & BDS-3 & BDS-4 \\
\hline \multirow[t]{4}{*}{250} & $10 \%$ & 91,94 & 75,95 & 80,07 & 96,30 & 98,09 & 99,39 & 99,36 \\
\hline & $5 \%$ & 87,67 & 70,52 & 72,18 & 93,12 & 97,38 & 99,07 & 99,17 \\
\hline & $2 \%$ & 82,05 & 64,39 & 62,98 & 87,96 & 96,08 & 98,69 & 98,72 \\
\hline & $1 \%$ & 78,04 & 59,85 & 55,55 & 83,18 & 95,18 & 98,26 & 98,36 \\
\hline \multirow[t]{4}{*}{500} & $10 \%$ & 99,90 & 83,85 & 87,86 & 99,96 & 99,93 & 99,94 & 99,94 \\
\hline & $5 \%$ & 99,82 & 80,54 & 83,45 & 99,91 & 99,91 & 99,93 & 99,94 \\
\hline & $2 \%$ & 99,58 & 76,43 & 78,00 & 99,82 & 99,87 & 99,93 & 99,93 \\
\hline & $1 \%$ & 99,35 & 73,64 & 73,80 & 99,75 & 99,81 & 99,93 & 99,93 \\
\hline \multirow[t]{4}{*}{1000} & $10 \%$ & 100,00 & 89,34 & 93,53 & 100,00 & 100,00 & 100,00 & 100,00 \\
\hline & $5 \%$ & 100,00 & 87,04 & 90,82 & 100,00 & 100,00 & 100,00 & 100,00 \\
\hline & $2 \%$ & 100,00 & 84,08 & 87,47 & 100,00 & 100,00 & 100,00 & 100,00 \\
\hline & $1 \%$ & 100,00 & 82,24 & 84,94 & 100,00 & 100,00 & 100,00 & 100,00 \\
\hline \multirow[b]{2}{*}{$n$} & \multicolumn{8}{|c|}{$y_{t}=0,5 \varepsilon_{t-1}-0,3 \varepsilon_{t-2}+0,5 \varepsilon_{t-1} \varepsilon_{t-2}+\varepsilon_{t}$} \\
\hline & $\begin{array}{c}\text { Poziom } \\
\text { istotności } \alpha\end{array}$ & LWZ & RESET^2 & RESET^3 & HAMILTON & BDS-2 & BDS-3 & BDS-4 \\
\hline \multirow[t]{4}{*}{250} & $10 \%$ & 51,82 & 77,01 & 83,32 & 69,42 & 62,98 & 78,81 & 81,55 \\
\hline & $5 \%$ & 42,82 & 70,78 & 72,59 & 59,81 & 54,22 & 71,95 & 75,47 \\
\hline & $2 \%$ & 32,99 & 63,26 & 56,48 & 48,41 & 44,72 & 63,14 & 67,55 \\
\hline & $1 \%$ & 27,23 & 57,45 & 45,10 & 41,29 & 38,30 & 56,65 & 61,27 \\
\hline \multirow[t]{4}{*}{500} & $10 \%$ & 88,43 & 89,20 & 95,51 & 98,46 & 87,99 & 97,01 & 98,12 \\
\hline & $5 \%$ & 83,38 & 86,29 & 91,50 & 97,30 & 82,98 & 95,42 & 96,75 \\
\hline & $2 \%$ & 76,36 & 81,47 & 84,12 & 94,89 & 75,86 & 92,46 & 94,28 \\
\hline & $1 \%$ & 70,64 & 77,80 & 76,79 & 92,57 & 70,37 & 89,39 & 91,98 \\
\hline \multirow[t]{4}{*}{1000} & $10 \%$ & 99,93 & 97,94 & 99,79 & 100,00 & 98,73 & 99,93 & 99,98 \\
\hline & $5 \%$ & 99,84 & 97,00 & 99,53 & 100,00 & 97,89 & 99,87 & 99,94 \\
\hline & $2 \%$ & 99,54 & 95,72 & 98,76 & 100,00 & 96,30 & 99,71 & 99,87 \\
\hline & $1 \%$ & 99,02 & 94,35 & 97,54 & 100,00 & 94,76 & 99,57 & 99,78 \\
\hline \multirow[b]{2}{*}{$n$} & \multicolumn{8}{|c|}{$y_{t}=0,5 y_{t-1}+0,3 \varepsilon_{t-1}-0,4 y_{t-1} \varepsilon_{t-1}+\varepsilon_{t}$} \\
\hline & $\begin{array}{c}\text { Poziom } \\
\text { istotności } \alpha\end{array}$ & LWZ & RESET^2 & RESET^3 & HAMILTON & BDS-2 & BDS-3 & BDS-4 \\
\hline \multirow[t]{4}{*}{250} & $10 \%$ & 99,24 & 86,93 & 99,94 & 99,37 & 97,78 & 99,06 & 99,00 \\
\hline & $5 \%$ & 98,60 & 83,99 & 99,82 & 98,41 & 96,30 & 98,39 & 98,31 \\
\hline & $2 \%$ & 97,32 & 80,01 & 99,53 & 96,27 & 94,06 & 97,20 & 97,10 \\
\hline & $1 \%$ & 96,10 & 77,06 & 99,24 & 94,14 & 91,92 & 95,80 & 95,79 \\
\hline
\end{tabular}


Ciąg dalszy tabeli 4

\begin{tabular}{|c|c|c|c|c|c|c|c|c|}
\hline 500 & $10 \%$ & $\mathbf{1 0 0 , 0 0}$ & $\mathbf{9 1 , 1 1}$ & $\mathbf{1 0 0 , 0 0}$ & $\mathbf{1 0 0 , 0 0}$ & $\mathbf{9 9 , 9 8}$ & $\mathbf{9 9 , 9 8}$ & $\mathbf{9 9 , 9 8}$ \\
& $5 \%$ & $\mathbf{1 0 0 , 0 0}$ & 89,34 & $\mathbf{1 0 0 , 0 0}$ & $\mathbf{1 0 0 , 0 0}$ & $\mathbf{9 9 , 9 6}$ & $\mathbf{9 9 , 9 8}$ & $\mathbf{9 9 , 9 8}$ \\
& $2 \%$ & $\mathbf{1 0 0 , 0 0}$ & 86,94 & $\mathbf{1 0 0 , 0 0}$ & $\mathbf{9 9 , 9 8}$ & $\mathbf{9 9 , 9 1}$ & $\mathbf{9 9 , 9 8}$ & $\mathbf{9 9 , 9 8}$ \\
& $1 \%$ & $\mathbf{1 0 0 , 0 0}$ & 84,99 & $\mathbf{1 0 0 , 0 0}$ & $\mathbf{9 9 , 9 7}$ & $\mathbf{9 9 , 8 3}$ & $\mathbf{9 9 , 9 8}$ & $\mathbf{9 9 , 9 7}$ \\
\hline 1000 & $10 \%$ & $\mathbf{1 0 0 , 0 0}$ & $\mathbf{9 5 , 0 3}$ & $\mathbf{1 0 0 , 0 0}$ & $\mathbf{1 0 0 , 0 0}$ & $\mathbf{1 0 0 , 0 0}$ & $\mathbf{9 9 , 9 9}$ & $\mathbf{9 9 , 9 9}$ \\
& $5 \%$ & $\mathbf{1 0 0 , 0 0}$ & 94,02 & $\mathbf{1 0 0 , 0 0}$ & $\mathbf{1 0 0 , 0 0}$ & $\mathbf{9 9 , 9 9}$ & $\mathbf{9 9 , 9 9}$ & $\mathbf{9 9 , 9 9}$ \\
& $2 \%$ & $\mathbf{1 0 0 , 0 0}$ & 92,84 & $\mathbf{1 0 0 , 0 0}$ & $\mathbf{1 0 0 , 0 0}$ & $\mathbf{9 9 , 9 9}$ & $\mathbf{9 9 , 9 9}$ & $\mathbf{9 9 , 9 9}$ \\
& $1 \%$ & $\mathbf{1 0 0 , 0 0}$ & 91,79 & $\mathbf{1 0 0 , 0 0}$ & $\mathbf{1 0 0 , 0 0}$ & $\mathbf{9 9 , 9 9}$ & $\mathbf{9 9 , 9 9}$ & $\mathbf{9 9 , 9 9}$ \\
\hline
\end{tabular}

Źródło: Śliwicki D. (2010), Estymacja jądrowa w analizie ekonometrycznej, Toruń, niepublikowana praca doktorska.

W grupie modeli nieliniowych szacowanych metodą największej wiarygodności test LWZ dał $100 \%$ bądź nieznacznie mniejszą moc dla szeregów posiadających 1000 obserwacji. Podobnie zachowuje się on dla modeli poddiagonalnego modelu dwuliniowego oraz diagonalnego modelu dwuliniowego ARMA. W porównaniu z testem Hamiltona osiągnięte wyniki pozwalają wysnuć wniosek, że zachowuje się on podobnie albo nieznacznie gorzej. W porównaniu $\mathrm{z}$ testem RESET zachowuje się on lepiej a w przypadku modelu dwuliniowego ARMA podobnie. W stosunku do testu BDS test LWZ dla modelu $y_{t}=0,6 y_{t-1} \varepsilon_{t-2}+\varepsilon_{t}$ zachowuje się gorzej, przypadku nieliniowego modelu średniej ruchomej test LWZ dal wyniki gorsze dla szeregów długości 250 i 500 obserwacji oraz podobne dla 1000 obserwacji. Dla modelu dwuliniowego ARMA moc testu LWZ jest podobna do mocy testu BDS.

\section{PODSUMOWANIE}

Na podstawie wszystkich przeprowadzonych symulacji można stwierdzić, że:

- test LWZ w przypadku modeli liniowych na ogół osiaga rozmiary mniejsze bądź zbliżone do nominalnych poziomów istotności,

- w grupie modeli nieliniowych szacowanych metodą najmniejszych kwadratów ${ }^{1}$ test LWZ wykazuje moc zbliżoną do zakładanej dla szeregów długości najczęściej 500 i 1000 obserwacji, a dla modelu SETAR(2) również dla 250 obserwacji; dla modelu NLAR(2) moc jest niewystarczająca dla wszystkich liczebności prób,

- w grupie modeli nieliniowych szacowanych metodą największej wiarygodności test wykazuje odpowiednio dużą moc dla szeregów o długości 1000 obserwacji a w przypadku modeli dwuliniowych również dla szeregów o 500 obserwacjach,

\footnotetext{
${ }^{1}$ Model SETAR(2) szacowany był warunkową metodą najmniejszych kwadratów.
} 
- dla modeli liniowych test LWZ w porównaniu z testem RESET dla zależności wielomianowej stopnia drugiego rzadziej odrzucał hipotezę o liniowości a dla zależności wielomianowej stopnia trzeciego na ogół częściej,

- w przypadku modeli nieliniowych trudno jednoznacznie wskazać na przewagę któregokolwiek $\mathrm{z}$ testów LWZ i RESET; dla pewnych modeli test LWZ wykazywał lepszą moc a dla innych sytuacja była odwrotna,

- dla modeli liniowych test LWZ w porównaniu z testem Hamiltona jest lepszy dla $1 \%$ i $2 \%$ poziomu istotności, dla $5 \%$ test LWZ jest na ogół lepszy a dla $10 \%$ wykazuje na ogół nieco gorsze rozmiary,

- dla modeli nieliniowych test LWZ odrzucał hipotezę o liniowości na ogół nie częściej niż test Hamiltona,

- w porównaniu z testem BDS test LWZ rzadziej odrzucał hipotezę o liniowości, gdy modele generujące były liniowe, a w przypadku modeli nieliniowych moc testu LWZ była wyższa bądź nie niższa od mocy testu BDS,

Ogólnie można wysnuć wniosek, że najbardziej wiarygodne wyniki badania testu LWZ uzyskano dla poziomu istotności równego $2 \%$, dla którego uzyskany rozmiar testu był zgodny z nominalnym. W przypadku $5 \%$ i $10 \%$ poziomu istotności uzyskano wyniki lepsze niż zakładano, natomiast przyjęcie $1 \%$ poziomu istotności wydaje się najbardziej ryzykowne.

\section{LITERATURA}

Brock W. A., Deckert W., Scheinkman J. (1986), A test for independence based on the correlation dimension, working paper, University of Winconsin at Madison, University of Houston, University of Chicago.

Brock W. A., Hsieh D. A., LeBaron B. (1991), Nonlinear Dynamics, Chaos and Instability: Statistical Theory and Economic Evidence, MIT Press, Cambridge.

Bruzda J. (2007), Procesy nieliniowe $i$ zależności dlugookresowe $w$ ekonomii. Analiza kointegracji nieliniowej, Wydawnictwo Naukowe UMK, Torun.

Fan Y., Li Q. (1996), Consistent Model Specification Tests: Omitted Variables and Semiparametric Functional Forms, „Econometrica”, 64, 865-890.

Hamilton J. D. (2001), A Parametric Approach to Flexible Nonlinear Inference, „Econometrica”, $69,537-573$

Li Q. (1999), Consistent Model Specification Tests for Time Series Econometric Models, „Journal of Econometrics", 92, 101-147.

Li Q., Wang S. (1998), A Simple Consistent Bootstrap Test For a Parametric Regression Function, ,Journal of Econometrics”, 87, 145-165.

Osińska M. (2008), Ekonometryczna analiza zależności przyczynowych, Wydawnictwo Naukowe UMK, Toruń.

Ramsey J. B. (1969), Tests for Specification Errors in Classical Linear Least-Squares Regression Analysis, „Journal of the Royal Statistical Society. Series B (Methodological)”, 2, 350-371.

Silverman B. W. (1986), Density Estimation for Statistics and Data Analysis, Chapman and Hall.

Śliwicki D. (2010), Estymacja jadrowa w analizie ekonometrycznej, Toruń, niepublikowana praca doktorska.

Zheng J. X. (1996), A Consistent Test of Functional Form Via Nonparametric Estimation Techniques, ,Journal of Econometrics”, 75, 263-289. 


\section{LINEARITY KERNEL TEST}

A b stract. The aim of this paper is to presents the results of simulation studies of size and power of the kernel linearity test, which belongs to a class of nonparametric tests. Simulation survey was carried out for linear and nonlinear models estimated by Ordinary Least Squares Method and Maximum Likelihood Method. The obtained results were compared with results of similar simulations for the RESET test, flexible Hamilton test and BDS test.

K e y w o r d s: kernel estimator, linearity testing, simulation. 